\title{
Embodied immersive design for experience-based learning and self-illumination
}

\author{
Keywords \\ Design ethics, Embodied design, Experience-based learning, Immersive learning, Self-illumination
}

Concept-based teaching and learning grounded on a mechanical paradigm has dominated western education tradition since the first industrial revolution. This type of educational tradition is characterised, among other things, by its reductionist and linear mindset that has led to siloed and disconnected knowledge generation. Yet the 21st Century demands us to rethink the traditional roles of the learner, the teacher and the learning environment. Climate change and wicked socio-ecological problems and challenges require a new 'tradition' to emerge, dominate and respond to our societal and planetary crisis. Integrated, multidisciplinary and transversal knowledge generation, dissemination and transfer, grounded on a strong critical ethics and philosophical exploration of new alternative educational paradigms, is paramount if we aim to respond accordingly to calls to create a better future today. Today's 4th industrial revolution fusing Artificial Intelligence ( $\mathrm{Al}$ ) with the Internet of Things (loT), genetic engineering, quantum mechanics and philosophy, and more is blurring the boundaries between the physical, digital, and biological worlds. This brings along the emergence of new understandings of the nature of human experience, and questions about how to design for it. In this scenario, education must become multidisciplinary again, where new epistemologies are to be the reflection of humanity's process of change and transformation, while reconnecting with old and ancient knowledge and ways of doing. In the past, knowledge was considered a 'unity' whole acquired through journeys in people's life, from where individuals learn by doing and experiencing every aspect of knowledge. One positive side-effect of embracing a unity view of knowledge today is that we can now make accessible non-western concepts, again, with emphasis on qualitative, subjective, emotional, embodied, ceremonial and spiritual views of knowledge generation and practice. How can we teach such concepts and views within a traditional and reductionist educational western system based on concept-based and siloed education? We cannot. Some knowledge, concepts and notions (known as 'Qualia' in the literature) can only be acquired through bodily lived and direct experiences. Today's digital immersive technology can make it easier to integrate and consume knowledge through digital visualisation and self-led user experiences. New media can afford to provide learners a good foundation on many different disciplines, which normally would take years to achieve based on traditional pedagogy. Experience-based mediums like virtual reality (VR), if used in a non-concept based way, can bridge the knowledge gap existing created by qualia subjects in western societies. Here we argue that the epistemology coming from the Santiago school of cognition, with notions such as embodiment, embodied cognition and enaction, can inform and guide the development of an experience-based type of immersive learning design based on an enactive, self-led user experience. We propose that immersive learning experience design ought to focus first and foremost on ethics and critical philosophy, followed by embodied design for experience-based self-driven illumination. In this presentation we review the conceptual background leading to some examples of current experienced-based learning and self-illumination design exploration in immersive learning design, informed by the epistemology coming from the Santiago school of cognition. 